\title{
Studies on Polyol Function in Aspergillus clavatus: a role for Mannitol and Ribitol
}

\author{
By D. L. CORINA AND K. A. MUNDAY \\ Department of Physiology and Biochemistry, \\ The University of Southampton, Southampton, $\mathrm{SO}_{9}{ }_{5} \mathrm{NH}$
}

\begin{abstract}
SUMMARY
Sugars produced by Aspergillus clavatus during growth on radioactive glucose were studied in order to establish roles for the major polyols in the general metabolism of the organism in submerged culture. From ${ }^{3} \mathrm{H} /{ }^{14} \mathrm{C}$ isotope-ratio patterns, it is concluded that the predominant function of mannitol is that of a storage compound, possibly connected with conidiation, while ribitol appears to be primarily involved in hydrogen-acceptor mechanisms. Isotopic stability of total fatty acids throughout growth was also observed.
\end{abstract}

\section{INTRODUCTION}

Since the discovery of mannitol and other polyols in micro-organisms they have been considered either to be involved in hydrogen-acceptor mechanisms (Helle \& Klungsoeyr, 1962) or to act as reserve carbohydrates (Birkinshaw, Charles, Hetherington \& Raistrick, I93I; Lee, 1967). When Aspergillus clavatus is grown in submerged culture with glucose as sole carbon source, mannitol is the predominant carbohydrate product; lesser amounts of ribitol, glycerol, sorbose and trehalose are also produced.

This paper reports some findings of investigations to determine the biochemical roles of these sugars in relation to the general metabolism of Aspergillus clavatus.

\section{METHODS}

Materials. [ $\left.\mathrm{U}^{14} \mathrm{C}\right]$ glucose and $\left[6^{3} \mathrm{H}\right]$ glucose were purchased from The Radiochemical Centre, Amersham, Buckinghamshire. Glucose 6-phosphate dehydrogenase (EC. I . I . I . 49), hexosephosphate isomerase (EC. 5.3.I.9), $\mathrm{NAD}^{+}, \mathrm{NADP}^{+}$and $\mathrm{NADH}$ were obtained from the Boehringer Corporation, London, W.5, fructose 6-phosphate from Sigma Ltd, London, S.W.6 and other reagents from British Drug Houses Ltd, Poole, Dorset. Mannitol I-phosphate was prepared by sodium borohydride reduction (Wolff \& Kaplan, 1956) of fructose 6-phosphate. Mannitol I-phosphate dehydrogenase specificity was assumed for the mannitol isomer of the resultant mixture of sorbitol and mannitol phosphates.

Organism and culture. Aspergillus clavatus was grown in submerged culture on glucose + salts medium. Pulse-labelling procedures with $\left[{ }^{14} \mathrm{C},{ }^{3} \mathrm{H}\right] \mathrm{glucose}$ were as previously described (Corina \& Munday, 197I) and for continuous growth on labelled glucose the pulse procedure was followed using unlabelled glucose with the final transfer to salts $+30 \mathrm{~g}$. $\left[{ }^{14} \mathrm{C},{ }^{3} \mathrm{H}\right]$ glucose/l. medium.

Quantitative and qualitative analysis of culture carbohydrates by gas-liquid chromatography $(G L C)$. Extracts of free neutral sugars were prepared from washed mycelial clumps and culture media (Corina \& Munday, 197I) without carrier but with the addition of 200 to $300 \mu \mathrm{g}$. arabinose internal standard as an aqueous equilibrium mixture. After deionization 
and evaporation in vacuo, I to $2 \mathrm{ml}$. of extract was freeze-dried and the carbohydrate trimethylsilyl (TMS) ethers prepared (Sweeley, Bentley, Makita \& Wells, 1963). Portions (I to $5 \mu \mathrm{l}$.) of the samples were analysed by GLC using a Pye I04 gas chromatograph (flame ionization detector) fitted with dual $5 \mathrm{ft} \times \frac{1}{4}$ in. glass columns packed with $3 \% \mathrm{E}-30$ silicone gum rubber on Diatomite C, I00 to 200 mesh. Conditions of chromatography were: analysing column nitrogen carrier flow-rate, $50 \mathrm{ml} . / \mathrm{min}$; injection port temperature, $280^{\circ}$; detector oven temperature, $300^{\circ}$; programmed column oven temperature, initial $190^{\circ}$ for $10 \mathrm{~min}$., $40^{\circ} / \mathrm{min}$. rise to $240^{\circ}$ for $25 \mathrm{~min}$. Analysis time $28 \mathrm{~min}$. to trehalose.

Components having mobilites identical with authentic mannitol, ribitol, $\alpha$ - and $\beta$ glucose, and sorbose were measured. Identities were further established by chromatography using a column of $20 \%$ diethylene glycol succinate on HMDS-Chromosorb W, 80 to 100 mesh, at $150^{\circ}$. Results were corrected to $100 \% \beta$-arabinose recovery and compared with quantitative standards.

Preparative GLC of radioactive carbohydrate components. Samples were prepared as for quantitative analysis with the addition of $\mathrm{I}$ to $5 \mathrm{mg}$. carrier of each sugar. After preparation of the TMS ethers, solvent was removed in vacuo at $30^{\circ}$, the sample extracted into ether and concentrated to $100 \mu \mathrm{l}$. Mixtures of ribitol, $\alpha$-glucose, mannitol, $\beta$-glucose and, in one series, sorbose, as I00 $\mu \mathrm{l}$. samples, were separated using a Pye I04 gas chromatograph on a $7 \mathrm{ft}$. $\times \frac{3}{8}$ in. stainless steel preparative column packed with $25 \%$ E-30 on Diatomite C, I00 to $200 \mathrm{mesh}$. Conditions were: $\mathrm{N}_{2}$ carrier flow-rate, $180 \mathrm{ml} . / \mathrm{min}$.; column temperature, $200^{\circ}$; injection port temperature, $300^{\circ}$; outlet heater, $270^{\circ}$. Time $75 \mathrm{~min}$. to $\beta$-glucose. The column effluent was split $(25: I)$, the major portion vented to the exterior where the eluting components were condensed in glass traps immersed in liquid nitrogen. The TMSsugars were flushed out with ether and the solvent removed before radioactivity determinations. Total recovery of radioactivity was 40 to $50 \%$.

Isolation of long-chain fatty acids. Radioactive fatty acids were isolated by direct saponification of freeze-dried mycelium (Stone, Butterworth \& Hemming, 1967) with the addition of $20 \mathrm{mg}$. carrier palmitic acid, and purified under nitrogen by standard methods (Ansari et al. 197I). The samples were dissolved in $2.0 \mathrm{ml}$. toluene prior to radioactivity determinations. Fatty acids for quantitative measurements were isolated from 100 to $250 \mathrm{mg}$. freeze-dried mycelium and determined gravimetrically.

Radioactivity determinations. Sugar TMS-ethers and fatty acid solutions were added directly to scintillation fluid and the radioactivity measured by liquid-scintillation spectrometry (Corina \& Munday, 1971).

Assay for mannitol synthesizing activity. Supernatants from centrifuged (100,000 $\mathrm{g}$ for I h.) sonicated mycelia were incubated I h. with $\left[6^{3} \mathrm{H}\right]$ glucose 6 -phosphate, deproteinized and hydrolyzed with $6 \mathrm{~N}-\mathrm{HCl}$ at $110^{\circ}$ for $\mathrm{I} 6 \mathrm{~h}$. Mannitol was isolated, with $15 \mathrm{mg}$. carrier, by chromatography on Whatman 3 MM paper using methyl ethyl ketone-acetic acid-water saturated with boric acid (9:I:I, by vol.) as solvent. After elution and freeze-drying, $5.0 \mathrm{mg}$. was taken for radioactivity determination as an aqueous solution. Protein was measured in the supernatants by the biuret method (Gornall, Bardawill \& David, 1948) and results calculated as ${ }^{3} \mathrm{H}$ c.p.m./mg. soluble protein.

High-speed supernatants from sonicated mycelia were investigated spectrophotometrically for mannitol I-phosphate dehydrogenase (EC. I I I I I I) activity by incubation with either fructose 6-phosphate and $\mathrm{NADH}$, or with mannitol I-phosphate + NAD ${ }^{+}$with and without phosphohexose isomerase and glucose 6-phosphate dehydrogenase $+\mathrm{NADP}^{+}$. Changes in optical density at $340 \mathrm{~nm}$. were recorded. 


\section{RESULTS AND DISCUSSION}

Enzymology of mannitol production. Oxidation of NADH by extracts of mycelia in the presence of fructose 6-phosphate demonstrated one of the established routes (Horikoshi, Iida \& Ikeda, 1965) for mannitol biosynthesis in this organism. Reduction of $\mathrm{NAD}^{+}$or $\mathrm{NADP}^{+}$in the reverse direction with mannitol I-phosphate as substrate was achieved only by addition of phosphohexose isomerase and glucose 6-phosphate dehydrogenase.

Investigation of the mannitol-synthesizing capability of mycelial extracts at various times during growth showed that the ratio c.p.m./mg. mannitol per mg. soluble protein maintained a constant value between 0.5 and 4 days' growth (Fig. I).

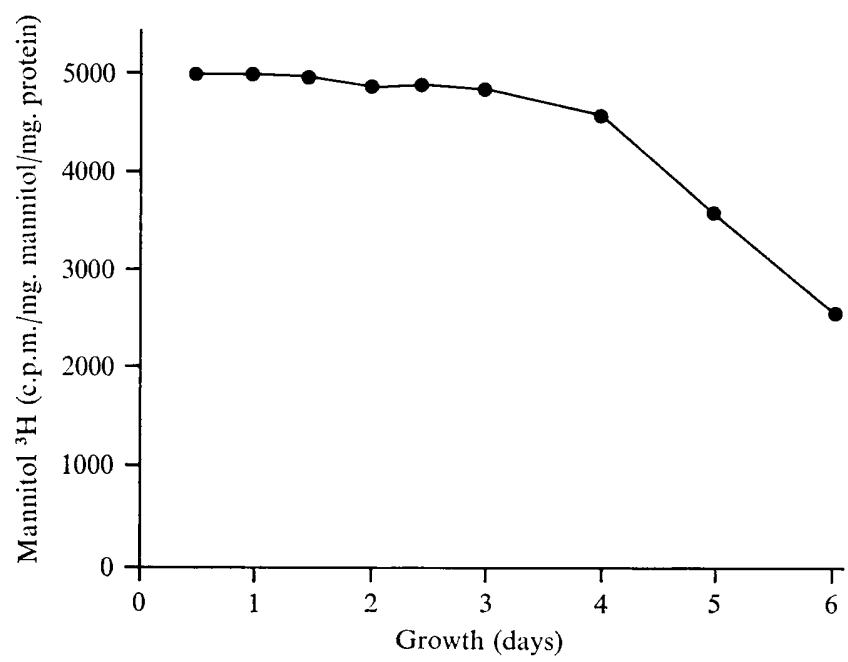

Fig. I. Mannitol synthesizing activity of mycelial extracts during growth on glucose. ${ }^{3} \mathrm{H}$ counts incorporated into mannitol from $\left[6^{3} \mathrm{H}\right]$ glucose 6-phosphate.

Quantitative and qualitative measurements on culture carbohydrate components. Changes in the major carbohydrate components within the culture during growth were determined (Fig. 2), the values representing the sum of separate measurements of filtered culture medium and sonicated mycelial clumps.

In addition to mannitol (Fig. 2a), ribitol was also present in the mycelium (Fig. $2 b$ ), but unlike mannitol, none was excreted into the medium. Throughout these changes there was an accumulation of a sugar tentatively identified as sorbose from GLC studies of retention data. The metabolic origin of this sorbose is as yet unknown, although ${ }^{3} \mathrm{H} /{ }^{14} \mathrm{C}$ labelling patterns (Table 2) would suggest a relationship with ribitol metabolism. Some ribitol accumulation was seen concurrently with mannitol synthesis but the greater part of ribitol synthesis and accumulation took place after mannitol reutilization. A small increase in the intracellular glucose level was also observed during mannitol reutilization. Traces of other carbohydrate components identified as glycerol, erythritol and trehalose were also detected, but being less than $5 \%$ of the total sugars were not measured in the present study.

Quantitative measurements of total fatty acids. Gravimetric analysis of total fatty acids (Table I) showed that after some initial utilization of spore lipids on germination, fatty 
acids were actively biosynthesized and stored until about day 4 . The levels then declined, presumably due to degradation.

$\left[{ }^{3} \mathrm{H} /{ }^{14} \mathrm{C}\right]$ glucose labelling experiments. In an attempt to demonstrate an involvement for mannitol in hydrogen-acceptor mechanisms, mycelium was grown either with a pulselabelling procedure using $\left[\mathrm{U}^{14} \mathrm{C}, 6^{3} \mathrm{H}\right]$ glucose and subsequent growth on unlabelled glucose (Table 2 ) or in the continued presence of $\left[\mathrm{U}^{14} \mathrm{C}, 6^{3} \mathrm{H}\right]$ glucose (Table 3) added after a pulse-procedure using unlabelled glucose to eliminate any biochemical effects of the pulselabelling procedure.

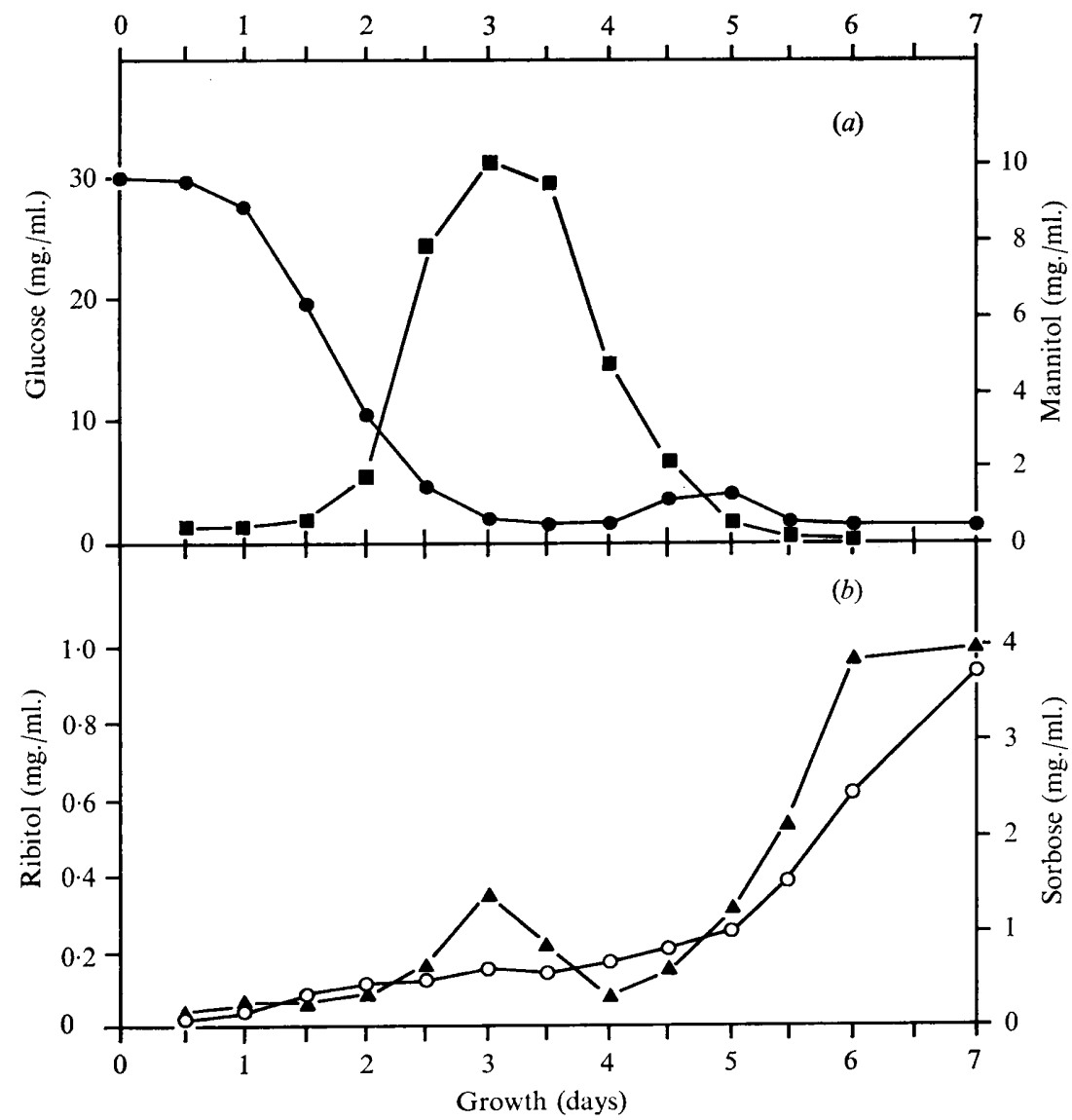

Fig. 2. Quantitative GLC analysis of major culture carbohydrates during submerged culture on $30 \mathrm{~g}$. glucose/l. + salts medium. (a) Glucose $(\boldsymbol{\theta})$, mannitol $(\boldsymbol{\square}) ;(b)$ ribitol $(\boldsymbol{\Delta})$, sorbose $(0)$, expressed as $\mathrm{mg} . / \mathrm{ml}$. total culture.

The various carbohydrates were isolated during further growth and their ${ }^{3} \mathrm{H} /{ }^{14} \mathrm{C}$ isotope ratios were determined, together with the ${ }^{3} \mathrm{H} /{ }^{14} \mathrm{C}$ ratios of total mycelial fatty acids. Under both conditions of labelling, the ${ }^{3} \mathrm{H} /{ }^{14} \mathrm{C}$ ratios of glucose and mannitol changed in parallel, (Table 2, 3), while the ${ }^{3} \mathrm{H} /{ }^{14} \mathrm{C}$ ratios of ribitol and sorbose remained elevated in the pulselabelled series (Table 2) and the ${ }^{3} \mathrm{H} /{ }^{14} \mathrm{C}$ ratio of ribitol increased in the continuous label series (Table 3). Similar but more pronounced decreases in post-pulse ${ }^{3} \mathrm{H} /{ }^{14} \mathrm{C}$ ratios were observed in glucose and mannitol isolated from $\left[6^{14} \mathrm{C}, 6^{3} \mathrm{H}\right]$ glucose pulse-labelled mycelia. 
The fatty acids isolated in both types of experiment show a relative stability of ${ }^{3} \mathrm{H} /{ }^{14} \mathrm{C}$ ratios, a slight increase being observed with continuous label (Table 3).

General discussion. In Aspergillus clavatus, mannitol synthesis was shown to be through established pathways, although reutilization of mannitol would not appear to be a simple reversal of these reactions (cf. Lee, 1967; Strandberg, 1969). An apparent lack of induction

Table I. Gravimetric determination of total fatty acids extracted after saponification of freeze-dried mycelial clumps

Mycelial clumps grown on salts $+30 \mathrm{~g}$. glucose $/ 1$. medium and harvested by filtration.

\begin{tabular}{|c|c|c|c|c|c|c|}
\hline Growth (days) & 0.0 & $2 \cdot 0$ & 3.0 & 4.5 & $6 \cdot 0$ & $7 \cdot 0$ \\
\hline $\begin{array}{l}\text { Fatty acid (mg./g.) } \\
\text { Mycelium }\end{array}$ & $\begin{array}{l}270 \quad 84 \cdot 9 \\
\text { (spores) }\end{array}$ & II 5 & 142 & $70 \cdot I$ & 20.4 & $20 \cdot I$ \\
\hline
\end{tabular}

Table $2 .{ }^{3} \mathrm{H} /{ }^{14} \mathrm{C}$ ratios of carbohydrate TMS-ethers and fatty acids from hyphae of Aspergillus clavatus after pulse-labelling

Mycelial clumps pulse-labelled $16 \mathrm{~h}$. in salts $+15 \mathrm{~g}$. $\left[\mathrm{U}^{14} \mathrm{C}, 6^{3} \mathrm{H}\right] \mathrm{glucose} / \mathrm{l}$. medium, transferred post-pulse to salts $+30 \mathrm{~g}$. unlabelled glucose/l. medium. Initial pulse ${ }^{3} \mathrm{H} /{ }^{14} \mathrm{C}$ ratio $=18 \cdot 0$.

$\begin{array}{cccccc}\begin{array}{c}\text { Days } \\ \text { post-pulse }\end{array} & \overbrace{\text { Glucose }} & \text { Mannitol } & \text { Ribitol } & \text { Sorbitol } & \text { Fatty acid } \\ 0.0 & 17.2 & 20.7 & 24.0 & 17.4 & 10.0 \\ 0.5 & 16.7 & 18.3 & 13.0 & 14.1 & 8.30 \\ 1.0 & 12.1 & 14.9 & 10.0 & 14.6 & 7.69 \\ 1.5 & 11.3 & 12.2 & 13.1 & 15.2 & 7.81 \\ 2.0 & 10.9 & 11.7 & 13.4 & 14.0 & 7.35 \\ 2.5 & 8.31 & 8.49 & 14.4 & 15.2 & 7.27 \\ 3.0 & 7.07 & 5.60 & 15.2 & 16.4 & 7.41 \\ 4.5 & 9.22 & 6.63 & 14.9 & 17.5 & 7.34 \\ 6.0 & 10.5 & 4.70 & 13.5 & 13.1 & 7.90\end{array}$

Table $3 .{ }^{3} \mathrm{H} /{ }^{14} \mathrm{C}$ ratios of carbohydrate TMS-ethers and fatty acids from hyphae of Aspergillus clavatus grown in the presence of labelled glucose Mycelial clumps grown in salts $+30 \mathrm{~g}$. $\left[\mathrm{U}^{14} \mathrm{C}, 6^{3} \mathrm{H}\right] \mathrm{glucose} / 1$. medium after a pulse-labelling
procedure $\left(\mathrm{I} 6 \mathrm{~h}\right.$.) in salts $+15 \mathrm{~g}$. unlabelled glucose $/ \mathrm{l}$. medium. Initial ${ }^{3} \mathrm{H} /{ }^{14} \mathrm{C}$ ratio $=\mathrm{I} \mathrm{I}^{\cdot} 5$.

$\begin{array}{ccccc}\begin{array}{c}\text { Days post } \\ \text { pulse-procedure }\end{array} & \text { Glucose } & \text { Mannitol } & \text { Ribitol } & \text { Fatty acids } \\ & { }^{3} \mathrm{H} /{ }^{14} \mathrm{C} & \text { ratios } & \\ 1.5 & 9.27 & 9.89 & 11.4 & 5.3 \mathrm{I} \\ 2.0 & 10.5 & 11.7 & 16.1 & 3.60 \\ 2.5 & 10.6 & 11.5 & 12.6 & 4.30 \\ 3.0 & 11.3 & 11.8 & 15.6 & 4.44 \\ 3.5 & 10.8 & 10.8 & 16.4 & 5.01 \\ 4.0 & 11.2 & 11.5 & 22.1 & 5.17 \\ 5.0 & 11.1 & 11.7 & 22.3 & 5.57 \\ 6.0 & 13.2 & 14.6 & 23.1 & 5.59 \\ & 13.1 & 13.0 & 24.5 & 5.19\end{array}$

of mannitol synthesizing activity (constant enzyme levels relative to cytoplasmic protein, Fig. I) indicated that the system was not induced by environmental factors such as oxygen tension during $\mathrm{I}$ to 4 days of the experimental period, and that the subsequent large production of mannitol was mainly due to overall increases in enzyme levels. It should be noted that fatty acids were also synthesized and accumulated during this same I- to 4-day 
period. Fatty acids, being the most reduced form of carbon in the organism, were considered a good indicator of hydrogen metabolism when investigated through ${ }^{3} \mathrm{H} /{ }^{14} \mathrm{C}$ isotope patterns and quantitative changes.

If the prime function of polyols was in hydrogen-acceptor mechanisms - for example, during fatty acid oxidation - it would be expected that such properties would be reflected in changes of ${ }^{3} \mathrm{H} /{ }^{14} \mathrm{C}$ ratios of both polyols and fatty acids with respect to glucose. In mannitol, no changes in ${ }^{3} \mathrm{H} /{ }^{14} \mathrm{C}$ ratios with respect to glucose were observed in either labelling system (Table 2,3), whereas the labelling patterns found in ribitol strongly suggest a role in hydrogen-acceptor function. This is supported by the observation that mannitol and fatty-acid biosynthesis occurred simultaneously, both systems being reductive processes. Ribitol accumulation took place after mannitol reutilization and during apparent fatty-acid degradation when a hydrogen-acceptor requirement might have been expected. Increases in culture aeration often radically change the polyol profile (Spencer \& Sallans, I956) in which mannitol production is invariably increased (Birkinshaw et al. I93I ; Smiley, Cadmus \& Liepins, 1967).

Preliminary analyses during conidiation of Aspergillus clavatus on glucose show that mycelia and conidia contained high levels of both mannitol and trehalose(D. L. Corina \& K. A. Munday, unpublished). In such systems, conidiation readily occurred between days 2 and 4, a period corresponding to high mycelial mannitol levels, whereas in submerged mycelia sporulation was suppressed, mannitol production remained high but trehalose levels were much reduced. Low trehalose levels in submerged culture may be attributed to the presence of sorbose, as this sugar is known to depress trehalose formation in Neurospora (Crocken \& Tatum, 1968). The biochemical significance of sorbose in A. clavatus is unknown; labelling patterns suggest a relationship with ribitol metabolism although a connexion with mannitol has also been postulated (Schoen \& Eras, 1937).

Much recent interest has centred round the enzymology of polyhydric alcohols in fungi (Spencer \& Sallans, 1956; Lee, 1967; Strandberg, 1969) but few attempts have been made to give definite functions to these various metabolic products. It is therefore proposed that although mannitol has a minor involvement in hydrogen-acceptor processes by virtue of its mode of biosynthesis, its primary function is that of a storage material in preparation for conidiation. Mannitol has been similarly implicated in sporulation of higher fungi (Rast, 1966) and also as a carbon source in germinating Aspergillus oryzae conidia (Horikoshi et al. 1965). In the absence of conidiation in submerged culture, mannitol is reutilized as a carbon source, in which capacity it may be acting as a substitute for trehalose. A similar phenomenon involving trehalose levels has been described for aconidial strains of Neurospora (Hanks \& Sussman, 1967).

In contrast, ribitol is believed to be produced solely as the product of hydrogen-acceptor mechanisms occurring during the utilization of storage materials such as fatty acids.

Further studies would therefore be of interest to determine the role of these polyols in conidiation processes together with investigation of the apparent isotopic stability of total fatty acids.

The authors thank the Lord Rank Research Centre for financial support. 


\section{REFERENCES}

Ansari, A. Q., Dolphin, P. J., Lazier, C. B., Munday, K. A. \& Akhtar, M. (I971). Chemical composition of an oestrogen-induced calcium-binding glycolipophosphoprotein in Xenopus laevis. Biochemical Journal 122, 107-I1 3.

Birkinshaw, J. H., Charles, J. H. V., Hetherington, A. C. \& Raistrick, H. (I93I). Studies in the biochemistry of micro-organisms. IX. On the production of mannitol from glucose by a species of Aspergillus. Philosophical Transactions of the Royal Society of London B 220, 153-171.

Corina, D. L. \& MUNDAY, K. A. (I97I). The metabolic stability of carbohydrates in walls of hyphae of Aspergillus clavatus. Journal of General Microbiology 65, 253-257.

Crocken, B. \& TATUM, E. L. (1968). The effect of sorbose on metabolism and morphology of Neurospora. Biochimica et biophysica acta 156, I-8.

Gornall, A. G., Bardawill, C. J. \& David, M. M. (1948). Determination of serum proteins by means of the biuret reagent. Journal of Biological Chemistry 177, 75I-766.

HANKs, D. L. \& Sussman, A. S. (1967). The relationships of trehalose and its metabolism to conidiation in Neurospora. Neurospora Newsletter II, 9-I I.

HeLLE, K. B. \& KLUNGSOEYR, L. (I962). Mannitol I-phosphate formation in Escherichia coli during glucose utilization. Biochimica et biophysica acta 65, 46I-47I.

Horikoshi, K., IIDA, S. \& IKEDA, Y. (1965). Mannitol and mannitol dehydrogenases in conidia of Aspergillus oryzae. Journal of Bacteriology 89, 326-330.

LEE, W. H. (1967). Carbon balance of a mannitol fermentation and the biosynthetic pathway. Applied Microbiology 15, I 206-1210.

RAST, D. (1966). Translocation of mannitol in fruiting bodies of Agaricus bisporus. Berichte der Schweizerischen Botanischen Gesellschaft 76, 176-184.

SCHOEN, M. \& ERAS, E. (1937). Quelques observations sur la fermentation appeleé mannitique. Enzymologia 4, 198-204.

Smiley, K. L., Cadmus, M. C. \& Liepins, P. (1967). Biosynthesis of D-mannitol from D-glucose by Aspergillus candidus. Biotechnology and Bioengineering 9, 365-374.

Spencer, J. F. T. \& Sallans, H. R. (1956). Production of polyhydric alcohols by osmophilic yeasts. Canadian Journal of Microbiology 2, 72-79.

Stone, K. J., Butterworth, P. H. W. \& HeMming, F. W. (1967). Characterization of the hexahydropolyprenols of Aspergillus fumigatus. Biochemical Journal 102, 443-455.

StrandBerg, G. W. (1969). D-Mannitol metabolism by Aspergillus candidus. Journal of Bacteriology 97, I305-1309.

Sweeley, C. C., Bentley, R., Makita, M. \& Wells, W. W. (I963). Gas-liquid chromatography of trimethylsilyl derivatives of carbohydrates and related substances. Journal of the American Chemical Society $85,2497-2507$.

WolfF, J. B. \& KAPLAN, N. O. (I956). D-Mannitol I-phosphate dehydrogenase from Escherichia coli. Journal of Biological Chemistry 218, 849-869. 